\title{
A PARTICIPAÇÃO COMO PRINCÍPIO DA GESTÃO DEMOCRÁTICA: O DEBATE PÓS DITADURA MILITAR
}

\author{
Maria Alice de Miranda Aranda ${ }^{1}$
}

\section{RESUMO}

Este artigo apresenta uma pesquisa bibliográfica feita nas produções acadêmicas produzidas no pós 1988 , sobre o princípio da participação, tema presente na intrincada relação entre gestão da educação, democracia, Estado e sociedade, categorias que alicerçam a Política Educacional Brasileira. Objetiva sintetizar como a academia vem respondendo às demandas em torno do mesmo e para tanto se utiliza de contribuições das áreas da Pedagogia, da Sociologia, da Política, da Economia. O diálogo estabelecido em torno do tema participação como princípio da gestão democrática da educação permite registrar retrocessos, avanços e lacunas, bem como os problemas oriundos de conceitos, concepções, finalidades e práticas diferenciadas, detectando projetos antagônicos de sociedade.

Palavras-chave: Participação; gestão democrática da educação; Estado; política educacional.

\section{PARTICIPATION AS A PRINCIPLE OF DEMOCRATIC MANAGEMENT: THE DEBATE AFTER MILITARY DICTATORSHIP}

\begin{abstract}
This paper presents a literature survey on academic productions produced in the post 1988 under the principle of participation present theme in intricate relationship between management education, democracy, state and society, categories that underpin the Brazilian Educational Policy. Aims to synthesize how the academy has been responding to the demands around the same and for both is used contributions from areas of Pedagogy, Sociology, Politics, Economy. The dialogue established around the theme of participation as a principle of democratic management of education allows to register setbacks, advances and gaps, as well the problems derived from concepts, conceptions, purposes and practices differentiated detecting antagonistic projects of society.

Keywords: Participation; democratic management of education; State; educational policy.
\end{abstract}

\section{Introdução}

A participação é entendida nesse estudo como um princípio democrático primordial, um preceito legal, uma categoria histórica que se constrói nas relações sociais e, em específico, na área educacional é um tema presente na intrincada relação entre a gestão da educação, o Estado e a sociedade, categorias que alicerçam a política educacional brasileira. Assim, objetivou-se uma síntese sobre algumas produções produzidas sobre o tema no pós 1988, um breve "Estado do Conhecimento", servindo-se de contribuições de pesquisas em educação no Brasil e além do Brasil, nas áreas da Pedagogia, da Sociologia, da Política, da Economia, numa constatação que as investigações que tratam da concepção de participação contemplam uma relação multidisciplinar. 
Entende-se por "Estado do Conhecimento" uma pesquisa de caráter bibliográfico que se propõe a organizar e discutir certa produção acadêmica, em diferentes campos do conhecimento. É uma avaliação sistemática da produção do conhecimento e está intimamente ligada ao progresso científico, contribuindo para o aprimoramento do conhecimento e direcionamento específico de uma determinada área, permitindo destacar a análise da produção científica como veículo capaz de revelar e expressar o que tem sido investigado, conhecendo, assim, o particular, o singular e assim ver manifestada a universalidade do conhecimento, em síntese, possibilita detectar avanços teóricos, bem como determinar lacunas e vieses, rupturas e descontinuidades.

Metodologicamente, num primeiro momento, efetivou-se o levantamento bibliográfico resultante de pesquisas buscadas em diversas fontes e de diferentes maneiras: bibliotecas, sites, Scielo, Google, bancos de teses, livros, etc., totalizando 180 produções das quais se selecionou um percentual de $30 \%$ (ou seja, cerca de 60 produções) que foram protocoladas de modo a ter informações para os seguintes itens: (1) identificação dos trabalhos (se dissertação/tese/artigo, livro, etc.): instituição, autor, título, orientador, ano de defesa, tipo de obra, editora, ano, periódico, título; (2) identificação do conteúdo: palavraschave, temática, objetivos, resumos; (3) conhecimento dos conteúdos presentes nas produções.

Num segundo momento, com o propósito de conhecer melhor os conteúdos presentes nas produções, buscou-se, na medida do possível, responder a questões como: Qual o problema que o (a) autor (a) se propõe investigar? Como o (a) autor (a) captura/aborda o problema? Como o (a) autor (a) apresenta a investigação? Qual o enfoque teórico: bases teóricas/ fontes teóricas? Quais os principais conceitos e/ou categorias de análise utilizadas? De que forma os conceitos são trabalhados no texto? A quais conclusões chega o (a) autor (a)? Quais questões podem ser apresentadas para debate? Quais as contribuições principais para a compreensão do objeto/temática/área do projeto de tese?

Num terceiro momento, para a elaboração deste estudo considerou-se necessário fazer recortes optando por sintetizar algumas questões oriundas do protocolo utilizado. Assim, primou-se por justificar a escolha da participação como objeto de pesquisa, na sequência, apreender a sua configuração no movimento teórico do pós 1988 e posteriormente captar lacunas, questões e possíveis propostas que poderão orientar outros estudos.

\section{A participação como objeto de pesquisa}

A gênese do estado do conhecimento aqui sintetizado foi base orientadora de estudos e investigações realizadas pelos autores deste artigo quanto à gestão e a política educacional, cujas constatações impulsionam cercar cada vez mais o tema da participação como objeto de pesquisa, vez que o aprofundamento do tema permite ampliar análise de concepções, finalidades e práticas diferentes presentes na área educacional e, em específico, no espaço escolar, oportunizando avanços em direção a qualidade social almejada tanto no social quanto no educacional (ARANDA, 2001, 2004, 2009; LIMA, 2011, 2012, 2013).

O primeiro estudo (ARANDA, 2001), ao buscar a distinção teórica entre o Projeto Político Pedagógico (PPP) e o Plano de Desenvolvimento da Escola (PDE), menciona programas, projetos e planos do governo federal na década de 1990, voltados para a educação básica oriundos, entre outros, da Conferência Mundial de Educação para Todos, ocorrida em Jontiem, na Tailândia (BRASIL, 1990), trazendo muitas propostas que buscam assegurar o êxito da educação por meio da participação da comunidade em geral, mas 
respondendo à medidas estatais que sinalizam para o sentido do "voluntarismo", ou participação voluntária. São destaques: o Plano Decenal de Educação para Todos - PDEpT (1993) que ao tratar do tema gestão da escola, orienta para a mobilização da sociedade e dos sujeitos diretamente envolvidos no processo, evidenciando a busca de elaboração de consensos, a afirmação de acordos, a negociação da participação. Note-se que, com o PDEpT iniciou-se o período de normatização das políticas educacionais (no Brasil, marco regulamentatório).

Outro Programa analisado nessa investigação foi o "Acorda Brasil. Está na hora da Escola!", criado em 1995, por iniciativa do governo federal com o objetivo de incentivar a sociedade a assumir sua parcela de responsabilidade em relação à qualidade da escola e da educação em todos os níveis, com ênfase no ensino fundamental. Assim, estimulava a participação de cidadãos, comunidades, entidades, poder público e empresas para a realização de parcerias com as escolas públicas.

Com o mesmo "espírito", também o Programa "Toda Criança na Escola", este voltado para o ensino fundamental e conclamando o envolvimento de toda sociedade para um "mutirão" em torno do objetivo proposto no título do programa, ou seja, viabilizar a regulação da tomada de decisão e a avaliação dos resultados de forma centralizada, ao tempo em que a execução era descentralizada, responsabilizando profissionais da educação, pais de alunos, empresários que foram chamados a participar (BRASIL, 1996).

Outro exemplo de iniciativa que envolveu a área privada foi o Programa "Amigos da Escola". Abraçado e divulgado pela Rede Globo desde o ano 2000 teve repercussão nacional ampla, incentivando a participação voluntária da comunidade na escola.

O segundo estudo (ARANDA, 2004) apresenta uma proposta de gestão democrática da educação fundamentado na democracia participativa de caráter popular, a "Constituinte Escolar". Proposta apenas, pois não chegou a ser traduzido em um Projeto de Educação. Ainda no processo de implementação, com a mudança da gestão política partidária e consequentemente com a substituição dos gestores educacionais foi interrompida, numa demonstração de que a concepção de participação popular não foi deveras "democrática", não logrou êxito na base estrutural da sociedade vigente, não alcançou a anunciada cidadania ativa, na busca de qualidade social na educação. Cidadania ativa, segundo Benevides (2000) é um princípio democrático e não um receituário político que pode ser aplicado como medida ou propaganda de um governo, sem continuidade institucional. 'Não é 'um favor' e, muito menos uma imagem retórica. É a realização concreta da soberania popular, [...] supõe a participação popular como possibilidade de criação, transformação e controle sobre o poder ou os poderes" (p. 19-20). E por qualidade social de educação entendida como uma concepção de qualidade que anda na contramão de um trabalho de reconstrução da educação, no sentido de ser uma atividade que realize a emancipação humana e social. Remete à construção de uma educação cuja qualidade esteja voltada para a formação de sujeitos capazes de produzir outras formas de relação econômica, social, cultural e política, superadoras das formas atuais (CAMINI, 2001).

O terceiro estudo citado (ARANDA, 2009), também demonstrou que o significado da participação na política educacional brasileira nos anos iniciais do século XXI, declarado no Plano Plurianual do Governo Lula (2004-2007) não demonstrou uma concepção plena de participação voltada para a promoção humana, para a qualidade social da educação, para a cidadania ativa, pelo contrário, faz jus a "cidadania ampliada" que permitiu chegar a seguinte tese: "[...] o significado do princípio da participação na política educacional brasileira [...] está fundamentado nos pressupostos da cidadania ampliada projetada pelos ideais liberais que visam ao bem-estar material ao nível da civilização vigente na sociedade capitalista [...]" (p.197). 
Seguindo o mesmo viés, Lima (2011) analisa a configuração da participação como uma prática de controle social por parte da sociedade em direção ao Estado. Em tal perspectiva o autor analisa que os conselhos presentes na educação, em particular o Conselho Municipal de Educação tem salutar importância como sujeito na configuração da política educacional municipal.

Em Projeto recente que articula pesquisa e extensão intitulado "A Participação da Comunidade na Gestão Democrática da Escola em prol da qualidade de ensino: o Projeto Político Pedagógico em questão" (LIMA, 2012/2015), em investigação realizada por meio de um processo de extensão realizado em escolas públicas de educação básica foi possível perceber que a participação como princípio da gestão democrática da educação ainda é um tema carente de estudos e que sua efetivação na gestão da escola passa pelos mesmos impedimentos teóricos, práticos e políticos, destacados nos estudos acima colocados, o que permite reafirmar a necessidade continuar a cercar o tema da participação como objeto de pesquisa, vinculando sempre com determinadas políticas sociais, das quais destacados a educação

\section{0 movimento teórico em torno do tema participação}

As produções teóricas sinalizadas oferecem apenas uma amostra frente ao grande universo de outras existentes e que serviram de base para as mesmas. Na continuidade, apresenta-se uma síntese e nesta a participação aparece mais como categoria explicativa do que como principal objeto de pesquisa e sempre acrescida de adjetivos como exemplo: democrática, pedagógica, cidadã, popular, como fórum, como competição, como mercado, terceirizada, restrita, mínima, camuflada, maquiada, tutelada. E ainda articulada a outras categorias convergentes e/ou divergentes, como as que seguem: neoliberalismo, globalização, democracia (representativa, participativa, direta, delegativa, deliberativa, semidireta), democratização (da sociedade, da educação), gestão da educação, políticas públicas da educação, referendo, plebiscito, qualidade de ensino, partidos políticos, autonomia, centralização, descentralização, trabalho, profissionais da educação, luta de classes, alienação, sociedade civil, hegemonia, consenso, dissenso, conflito.

As pesquisas levantadas, no geral, trazem como objetivos: estudar o processo de democratização do sistema educacional de modo a compreender as intricadas relações na construção democrática da gestão educacional na década de 1990; analisar como a política do período efetiva-se na escola, local de realização da democratização da educação; apreender a concepção de gestão democrática e de democracia presentes em projetos, programas e planos e como se configura a articulação entre ambas; entender o que é implementado como democracia participativa e as contradições entre o discurso e a política pública; investigar a questão histórica da democratização nas sociedades de capitalismo desenvolvido e em desenvolvimento; debater criticamente sobre as concepções, posições e perspectivas que perpassam o tema da democracia; perceber a desarticulação entre as funções sociais e econômicas do estado brasileiro; propor questões pertinentes à implementação e às condições de viabilidade e eficácia dos mecanismos de participação direta na atividade de produção de leis e de políticas governamentais; chamar a atenção para as concepções presentes nos adjetivos que qualificam a participação.

As pesquisas em foco, na sua maioria, têm como perspectiva teórica a Ciência da História, também denominada de materialismo histórico (MARX) ou filosofia da práxis (GRAMSCI), primando por uma caminhada teórica fundamentada na categoria da totalidade, buscando a relação entre o singular e o universal e nessa relação desvelar as mediações e as contradições presentes no propósito anunciado, ou seja, a possibilidade de 
sair do empírico para o concreto pesado, alcançando abstrações científicas. Como minoria, outras perspectivas teóricas como o pluralismo, o estruturalismo, positivismo.

Metodologicamente, as produções concretizam suas investigações pautadas nas pesquisas bibliográfica, documental e de campo, observando critérios quantitativos e qualitativos. Documentos e situações do período são exaustivamente estudados, sustentados pela análise epistemológica e postos e contrapostos na consideração de compreensões e concepções de sujeitos históricos de pesquisa, utilizando-se no geral, de questionários, entrevistas estruturadas e semi-estruturadas.

Quanto ao conteúdo, no geral as investigações mostram que historicamente e com prevalência no pós 1988, a forma de participação das pessoas no Brasil tem mostrado que a democracia não tem conseguido se articular a uma concepção que legitime seus próprios valores, e, empiricamente é afirmado por muitas bocas que a participação é reduzida, é restrita, é mínima, etc.

Senna (1994), pesquisando o tema da democracia, trouxe para o debate a produção pedagógica sobre a articulação entre educação e democracia, no período de 1979-1988, por meio de duas revistas de circulação nacional: Revista Educação e Sociedade e Revista da ANDE. A escolha dessas duas revistas baseou-se no fato de ambas pertencerem a duas entidades cientificas, ANDE (Associação Nacional de Educação) e CEDES (Centro de Estudos Educação e Sociedade) e, enquanto movimento específico da educação no Brasil, teve o mérito de engajar na luta por democracia nos anos 1980, fato que contribuiu para os educadores encontrassem novo ponto de partida. A autora desvenda concepções, posições e perspectivas que mostram a desarticulação entre as funções sociais e econômicas do estado brasileiro, principalmente porque esta desvinculação ocorre em um momento em que o estado propõe a democratização da sociedade. Sugere, assim, que o estudo das relações entre educação e democracia deve ser orientado de modo a negar a perspectiva que enquadra a democracia nos limites do requerimento do capitalismo e da administração estatal, de modo a descartar posicionamentos que apregoam que a participação da população não tem sentido ao parecer "[...] que tudo o que há de essencial e substantivo está previamente decidido" (DI GIORGI, 2004, p. 120).

Mas O'Donnell (1994) chama a atenção para o fato de que o comportamento dos cidadãos não é resultado de uma predisposição dos mesmos em privilegiar a informalidade, a apatia ou a alienação, mas respostas oriundas do modo como a democracia vem se configurando na atual sociedade. Tal explicação remete a Coutinho (2002), quando este autor lembra épocas na história que o liberalismo apresentava-se como alternativa à democracia e que no século XX, a partir dos anos 1930, o "liberalismo assume a democracia e passa a defendê-la, mas, reduzindo-a, minimizando-a, empobrecendo suas determinações, concebendo-a de modo claramente redutivo" (Ibid.). Nesse sentido, o autor ainda alerta: "[...] quando hoje nos dispomos a avaliar uma teoria ou uma situação concreta como sendo ou não democrática, temos que saber de qual concepção de democracia estamos falando" (p.21).

Kinzo (2001) como Senna (1994), lembra que no Brasil foi inaugurada em meados de 1985 a fase de intensificação da democratização, para nós, marco reivindicatório. Os sinais mais importantes foram a instituição de condições livres de participação e contestação (com a revogação de todas as medidas que limitavam o direito de voto e de organização política) e, acima de tudo, a refundação da estrutura constitucional brasileira com a promulgação de uma nova Constituição, a 1988. Mas as mudanças não se davam apenas na esfera política. Na esfera social, as extremas desigualdades sociais constrangiam a consolidação da democracia, especialmente no que se refere a efetiva participação política de todos os cidadãos. 
Percebe-se que dado o contexto social e político no qual se processou a (re) constitucionalização do país, o novo estava fadado a conviver com o velho. Oliveira (2000) faz referência à "questão do novo ou tudo de novo". Analisando tal raciocínio (O'DONNELL, 1994; WEFFORT, 1992; HAGOPIAN, 1992), a oposição democrática foi cooptada no Brasil pela ideia da transição negociada e este processo garantiu a permanência na política brasileira de seus antigos vícios, ou seja: a prática desenfreada do clientelismo político, a fragilidade e a falta de opções programático-ideológicas dos partidos, e o comprometimento das instituições democráticas com o poder privado.

Assim, em âmbito do brasileiro, no pós 1988, grande número dessas pesquisas menciona a participação em conexão com a política educacional implementada na década de 1990 a partir da análise de Programas e Projetos de Gestão Democrática, chamando a atenção para a ressignificação de categorias e processos que resultam em novas formas de regulação da gestão da educação.

Daros (1999), em tese intitulada "Em busca da participação: a luta dos professores pela democratização da educação" investigou como ocorreu, na década de 1980, em Santa Catarina (SC), a ampla mobilização dos professores em torno da participação com possibilidade de influir na formulação das políticas públicas e, por consequência, influir nos centros de poder, especificamente no campo educacional. Constatou que professores da rede pública, relacionando-se com o Estado enquanto sujeitos coletivos (constituindo um tipo particular de movimento social) estabeleceram com o governo um confronto (tensão na forma de participação: disputas político-ideológicas), mostrando um grande poder de articulação e mobilização em torno das questões consideradas prioritárias (eleição de diretores, o estatuto e o plano de cargos e carreira, a questão do sistema de avaliação escolar). Estava sendo elaborada uma nova política de forma participativa (além dos professores, a participação da comunidade), vez que o movimento dos professores soube aproveitar as fraturas do poder e demonstrou enorme capacidade de se organizar e se mobilizar em torno das questões julgadas de maior interesse da categoria, respondendo também aos anseios populares de recuperação da escola pública. Mas o convívio mais próximo com o processo decisório demonstrou que ainda faltava a eles a possibilidade de estabelecer estratégias e procedimentos que dessem conta de superar a estrutura de uma agência governamental ainda muito impregnada dos valores do Estado autoritário.

Nas produções acadêmicas que trazem o estado de Mato Grosso do Sul (MS) como campo empírico, Fernandes (2000) discute a gestão democrática, tema considerado como elemento central da política educacional realizada no período de 1991 a 1994, que na prática escolar, culminou com a eleição para diretor de escola e a eleição do colegiado escolar como órgão consultor e executor do processo administrativo e pedagógico da escola. A autora mostra que na política educacional do período, a gestão democrática e sua participação revestem-se de um discurso inovador, mas que na prática se verifica a partilha da gestão com a comunidade de forma tutelada pelo Estado. Adverte a autora que a democracia representativa, fórmula que a democracia liberal encontrou enquanto projeto político de classe, ao trabalhar o conceito de participação, entre outros, tem feito um uso restrito dos mesmos. Restrição que faz com que a democracia se apresente com nuances de difícil compreensão para o conjunto da população e a participação como um mecanismo controlado pelo projeto político de classe. A autora frisa que "a democracia não é somente um fator de igualdade política em que todos participam, mas antes de tudo um estado que permite a igualdade econômica e política" (p. 144).

Figueira (1998) também analisa a política educacional do MS relacionando-a com as mudanças em curso no capitalismo mundial. Chama a atenção para o fato de que a democratização, ao ser analisada a luz das mudanças no capitalismo mostra uma nova 
configuração em que a educação passa a ser entendida pelo viés economicista, ou seja, pensada como investimento.

No estado de Mato Grosso (MT), Cardoso Neto (2004), se propôs a estudar o processo de democratização da educação, focando para o tema da participação. $\mathrm{Na}$ sua pesquisa analisa a relação dialética explicitada por ex-secretários de educação e sindicalistas que na década de 1990 "tiveram papel preponderante na formulação de um projeto de democratização da educação que se apresentou descentralizador e autônomo, com vistas a elevação da qualidade social da educação, em nome da inclusão, da emancipação, da solidariedade e da cidadania" (p. 23), mas que não passou do caráter pontual, ou seja, mudam-se as pessoas, mudam-se os projetos.

No estado do Ceará (CE), Ramos (2004) ressalta mudanças ocorridas a partir de seu projeto de democratização da gestão da educação (Gestão Colegiada) apenas na apropriação dos adjetivos, ou seja, adotando um que qualifica a participação, mas que na constituição desse projeto a participação se esvazia por não ter significado prático. A contradição evidenciada encontra-se no fato de que a gestão democrática "está constituída no princípio de fazer a sociedade acreditar que participa, sem fazê-lo de fato" (p. 191, grifos nossos). O modelo de projeto político adotado no Ceará "nega o clientelismo [...], mas promove uma cidadania assistida que dá a noção de direito à participação maquiada, ou seja, assistida" (p. 186, grifos nossos).

Focando o olhar para O Distrito Federal (DF), Brasília, a capital do Brasil, Costa (1994) analisa a percepção do sistema educacional do DF sobre o processo democrático na gestão administrativa, em duas escolas de ensino fundamental e médio da rede oficial de ensino e sua relação direta com o processo técnico-pedagógico, observados no cotidiano escolar. Analisa o impacto da qualidade de ensino no processo de gestão democrática a partir das categorias participação, autonomia e compromisso, a luz dos critérios dos paradigmas multidimensionais de eficiência, eficácia, efetividade e relevância. Estabelecido os parâmetros do modelo teórico adotado pela instituição educacional e a prática democrática observada, chega às seguintes conclusões: ausência de reflexão mais aprofundada sobre a concepção democrática no processo educativo; a política administrativa da instituição pública não favorece avanços considerados significativos; a democratização restrita a elaboração de planos de ação devido a escassez de recursos. Mas o autor adverte que apesar de pouca participação, o processo democrático continua sendo uma aspiração da comunidade escolar.

Indo para São Paulo, Silva (1990) em sua tese "Democracia e educação: a alternativa de participação popular na administração escolar" buscou compreender o fenômeno da participação dos usuários na administração da unidade escolar, entendendo que essa participação é uma das condições para a conquista de uma sociedade democrática. Percebida a viabilidade teórica da participação investigou nove escolas públicas da capital paulista integrantes das redes municipal e estadual, sobre a respectiva possibilidade concreta de realizar essa participação. Demonstrou ao final do estudo, que a forma de organização dos usuários é fator preponderante para uma efetiva participação dos mesmos na administração da unidade escolar.

Caminhando um pouco mais em terras brasileiras e extrapolando um pouco o espaço educacional, o livro "A inovação democrática no Brasil", de Avritzer e Navarro (2003) apresenta uma variedade de estudos com o tema participação política, ressaltando ser o mesmo ao mesmo tempo inovador e polêmico. Os autores examinam as experiências de funcionamento do orçamento participativo (OP) em diversos municípios brasileiros dos estados do Rio Grande do Sul, Santa Catarina, Pernambuco. Frisam que o pano de fundo das análises desenvolvidas no livro em tela é a cidade de Porto Alegre, local em que o OP foi implantado pela primeira vez, como experiência de participação popular, em 1989, 
durante administração do Partido dos Trabalhadores (PT). É conferido ao orçamento participativo o caráter de inovação institucional, inspirada na ideia de democracia participativa e que busca várias formas de articulação entre as democracias participativa e representativa, demanda, portanto, várias adaptações que resultam em uma complexa "engenharia de participação".

Silva (2003) lembra um experimento específico de participação popular em locais do Nordeste, afirmando que essas iniciativas são promissoras, em particular porque buscam ampliar o espaço de participação da população na política local. Mesmo com a clareza dos entraves provenientes de fatores estruturais e superestruturais são experimentos de participação que devem ser olhados com seriedade por parte da academia, de modo a serem explicitados epistemologicamente.

Neves (2002) chama a atenção para a questão da participação no Brasil, mostrando que está nesse princípio o ponto mais intrigante da política em voga, a sua contradição. A comunidade é chamada a participar, só que a forma de participação denota um sentido camuflado, e não é percebido pelos sujeitos históricos o autoritarismo crônico presente na concepção de participação e a própria correlação de forças pelo poder dentro das instituições não deixa entrever os limites impostos a essa participação. É uma participação consubstanciada pelo associativismo estimulado pelo bloco no poder, pela defesa de interesses que despolitizam a política, vez que não relaciona questões de natureza específica com os problemas conjunturais e estruturais da sociedade. Segundo a autora ainda enfatiza que hoje, na concepção em análise, a participação tem uma nova forma: o voluntarismo. "O voluntarismo [...] é mais uma faceta da política de despolitização da sociedade, [...] práticas coletivas de participação são substituídas por práticas individualizantes" (p.172).

Rosar (1999) analisa que os ganhos consagrados na Constituição de 1988 não lograram o êxito desejado pelos educadores compromissados com uma sociedade e uma educação mais justa e digna. Mas são restrições de caráter legal que não poder se constituir em fatores absolutamente impeditivos para que se aprofundem experiências democráticas.

Caminhando para além do Brasil, tem-se Castilla Urbina (1997), que aponta a decomposição do sistema educacional da Nicarágua submetido à política neoliberal após os anos da revolução sandinista, o que resultou numa política fragmentadora, orientada para a privatização, dependente dos organismos internacional, antidemocrática, carente de equidade e ineficiente no sentido que exclui os mais pobres do processo de participação social, e, como decorrência, do educacional.

Também em âmbito mais geral, Girardi (1994), mostra propostas educacionais que vêm sendo consideradas alternativas de solução para a retomada do desenvolvimento econômico dos países da América Latina e Caribe. Situação lembrada por Tuppy (1998), que chama a atenção para o fato de que os objetivos educacionais de emancipação social foram relegados em favor de mecanismos da racionalidade produtiva que se vinculam aos próprios objetivos de acumulação capitalista, resultando na captura da educação pela economia.

Boron (2001) ressalta que entre as metas globais que hoje em dia são propostas pela grande maioria das forças progressistas da América Latina e que resumem boa parte das reivindicações que os partidos populares têm exigido está a democracia participativa. Meta esta que aparece entre as "formulações gerais [...] de um chamado [...] a discutir e promover um ambicioso programa de transformações sociais" (p. 227).

Foi possível detectar, com base no movimento teórico em torno da participação, tanto no Brasil, como além dele, que a participação, tanto quanto o Estado e a própria democracia vem dando as respostas "corretas" às perguntas feitas pelo sistema capitalista, mas muitas outras questões continuam sem respostas e mesmo uma política de esquerda 
não chegará a respostas que venha a indicar sucesso no interior dessa democracia, apenas poderá minimizar os efeitos reprodutivos favoráveis à ordem social dominante.

\section{Lacunas, questões e propostas}

Considerando as contribuições das pesquisas delineadas percebe-se a caminhada significativa empreendida pela academia com vistas a oferecer subsídios para a continuidade de outras pesquisas, vez que o conhecimento está em processo e nada está pronto e acabado.

Assim, faz-se destaque para outros teóricos que nas suas produções oferecem contribuições para a continuidade do conhecimento epistemológico sobre o tema em foco. Martins (2005), por exemplo, em artigo intitulado "Vinte anos de democracia?" apresenta vários questionamentos relativos ao tema em questão: que reflexões nos vêm à mente quando nos perguntamos o que aconteceu com a democracia no Brasil ao longo dessas últimas duas décadas? Concluiu-se a famosa transição do autoritarismo à democracia? $\mathrm{O}$ novo regime implantou-se? E, daí em diante, que aconteceu? A democracia fortaleceu-se, expandiu-se, radicalizou-se? O mesmo autor responde que ao contrário do se que poderia esperar - na qualidade de cidadãos que supostamente vivem numa república democrática - o regime em vigor promove no seio da população elevadas taxas de absenteísmo político e ideológico. O que fazer para camuflar a ausência do povo - esse vazio inexplicável e imperdoável? Como quem não tem cão, caça com gato, o regime abriu espaço para a participação política terceirizada. $\mathrm{O}$ autor ilustra tal forma de participação lembrando as campanhas eleitorais, assim como a propaganda partidária entre as eleições que foram entregues a pessoas estranhas ao serviço. Na base, milhares de pessoas que sacodem bandeiras a dez reais por dia. Na cúpula, "marqueteiros" que comandam a fala dos candidatos e repetem na esfera pública o que aprenderam a fazer nas empresas de publicidade comercial: pirotecnia e publicidade enganosa. Essa terceirização da participação política assume também a forma de um sem número de organizações nãogovernamentais especializadas nos mais diversos setores de atividade que vistas em conjunto, compõem um quadro colorido, aquela variada multiplicidade que é perfeitamente concorde com o espírito e a letra do pluralismo liberal.

O autor chama também a atenção para a participação política e social que deveria movimentar os sindicatos e os movimentos sociais. Nos sindicatos é grande a despolitização. Frisa que os sindicatos apresentam hoje uma vida vegetativa, passando por crise de militância, fazendo campanha de filiação na base de rifa e de "showmícios".

Quanto aos movimentos sociais, ao mesmo tempo em que conseguiram, em parte, se institucionalizar, entraram numa espécie de refluxo. Refluxo de vitalidade e de representatividade, alimentado pela opção preferencial pelas ONGs, cujo número e cuja variedade se multiplicam sem cessar.

Nogueira (2003), tomando como parâmetro o conceito de sociedade civil elaborado pelo marxista italiano Antonio Gramsci, dialoga, em seu artigo, com as demais ideias de sociedade civil que hoje buscam se afirmar no panorama político e cultural. Seu principal argumento é que, nas últimas décadas, transitou-se uma ideia de sociedade civil como campo predominantemente político-estatal, palco de lutas democráticas e novas hegemonias, para uma imagem que converte a sociedade civil em recurso gerencial destinado a viabilizar tipos específicos de políticas públicas. Argumenta o autor que a incorporação da ideia de participação à linguagem do planejamento fez com que a sociedade civil se deslocasse de seu campo principal (o da organização de novas hegemonias) e se convertesse num espaço de cooperação e gestão da crise. De uma fase em 
que o marxismo preponderava nas discussões e deixava sua marca, ingressou-se numa fase em que a perspectiva liberal, afirmada de modo ortodoxo ou nuançada, prevalece e opera como referência principal.

Martins (2005) lembra que depois que os militares regressaram à caserna e a seus deveres de ofício, se tem de um lado a realidade que aí está e, de outro, o termo "democracia" utilizado para designar o estado de coisas supervenientes. E questiona se existe adequação entre esses dois lados. Se sim, chegou-se ao que foi previsto pela tese de transição. Se não, urge continuar a refletir sobre o assunto. Adverte ainda que à medida que se avança na reflexão, avança-se também na perplexidade, mas que é preciso decifrar o enigma colocado. Sales (2005) reconhece o fato de que a democracia vem gozando da importância e significado histórico que tem, não poderia ser menos manuseada do que é. Mas reconhece, igualmente, que os emaranhados próprios do assunto, somados à intensidade e à complexidade dos diálogos entre os autores, tornam o tema um Everest, cuja escalada plena requer ainda muitos anos de pesquisa.

Como se vê, as lacunas são muitas, mas as propostas também. E em específico sobre o tema participação, Benevides (2000) ressalta que o mesmo não é novo, ainda foi pouco estudado no Brasil e que um número relevante de estudos se "apóia, sobretudo, em material bibliográfico e documental sobre a "legislação direta" nos Estados Unidos (directlegislation) e sobre as formas de democracia semidireta nos países europeus, com destaque para a Suíça, a Itália e a França” (p. 11). Argumenta que o assunto não entusiasma a maior parte dos cientistas políticos brasileiros, "alguns dentre eles talvez considerem que se trata de um 'tema menor' - ao contrário, por exemplo, dos 'temas nobres' da representação, dos partidos políticos, dos sistemas de governo, [...], dos debates sobre o papel do Estado [...]" (p. 11). Observa ainda que "a participação popular, muitas vezes é associada a uma nova "doença infantil do esquerdismo" própria dos nostálgicos da democracia dos antigos [...]” (Ibid.). Segundo a autora os mecanismos de participação em foco são "ora identificados com um populismo inibidor dos verdadeiros 'anseios democráticos', ora vistos como formas sofisticadas de participação popular, válidas apenas para os países superdenvolvidos" (p.11). Mas afirma que o tema da democracia e da democratização permanece "nobilíssimo" e com bons trabalhos a respeito, mas que "inexiste [...] uma reflexão aprofundada sobre a efetiva soberania popular, soberania na prática e não apenas na retórica" (p.12).

Cardoso Neto (2004) observa que o tema da democratização da educação não é simples de ser interpretado, há muitas possibilidades para compreendê-lo e outras tantas para não compreendê-lo de forma alguma, vez que ainda prevalecem problemas de concepção quando se discute um projeto de governo, de sociedade, de modelo econômico e consequente de educação. Problemas que remetem a análise de Spósito (1990) ao afirmar que o tema da participação se transformou em uma corrente, quase um lugar comum, se faz necessário "aprofundar a reflexão, pois a questão envolve maior grau de complexidade do que aparenta" (p. 52).

\section{Considerações Finais}

Considerando o objetivo central deste estudo, cabe reafirmar que os pontos destacados sobre o tema participação em convergência com as categorias que o sustenta (democracia, Estado e sociedade) possibilitou constatar que no pós 1988 o tema da participação é apresentado nas produções científicas num emaranhado de desafios de ordem teórica, metodológica e temática. 
Quanto à temática, se faz necessário, considerando os vários adjetivos que qualificam a participação, entende-la quanto às práticas daí sugeridas, bem como as finalidades, concepções subjacentes e bases teóricas.

Teoricamente, constata-se a crítica às perspectivas que defendem a forma de participação liberal/neoliberal necessária ao capitalismo e defendem a participação realmente constituinte e constitutiva de um projeto de sociedade que se apresente diferente desta que aí está. Exemplo cabal está nas palavras de Mészáros (2003), no livro "Século XXI: socialismo ou barbárie". Neste, o autor mostra a conformação agressiva dos Estados Unidos nesta fase de profunda destruição ambiental, precarização do trabalho, massacre dos povos, perda dos sentidos e dos significados humanos e societais, impondo ao mundo uma política destrutiva em sua forma quase limite. $\mathrm{O}$ autor chama a atenção para o fato da solicitação que historicamente vem sendo feita à classe trabalhadora no sentido de ser unida internacionalmente e ser dotada de consciência de classe, e, adverte: "O capital não vai ajudar, nem fazer tamanho 'favor' à classe trabalhadora pela simples razão que é incapaz de fazê-lo" (p. 99). E complementa: "É compreensível, portanto, que toda a conversa sobre 'divisão de poder' com os trabalhadores, ou de 'participação' deles nos processos de decisão do capital pertence ao reino da pura ficção, ou de uma camuflagem cínica do real estado das coisas" (p. 100). Mészáros é um pensador que não vê outra solução para a humanidade que não a abolição do capital.

Metodologicamente, as produções estudadas apresentam propostas que concebem a participação popular como propulsora dos movimentos sociais, mas sem relacionar a necessidade da "participação" estar aliada às questões do conhecimento científico. Fimus (1996) conclama a recuperação da educação enquanto prática democrática e denuncia uma ordem autoritária e excludente de participação popular. Afirma o autor que está nas condições de aprendizagem sustentadas pelo Estado, a plena participação dos cidadãos no conjunto das instituições sociais.

Setubal (1997) enfatiza as práticas educacionais democráticas populares como articuladoras das políticas, mas esta articulação depende de uma gestão participativa, cuja concepção de democracia deve visar a promoção humana. Segundo Bobbio (2002) as práticas educacionais democráticas populares não se enraízam em instituições mediadas por aparelhos de controle produzidos e dirigidas pela classe hegemônica, detentora do poder político. O que vem acontecendo é que essas práticas democráticas populares têm funcionado apenas como meios de pressão e não chegam a novas formas de sociabilidade e de poder. Bobbio ainda afirma que muitas das alternativas democráticas que objetivam um caminho que direcione para a transformação da sociedade, mesmo quando chegam a se realizar sob a forma da democracia de base ou de massa, são absorvidas pelas organizações partidárias de cunho clientelístico ou de cunho burocrático que manipulam decisões e idéias à sua revelia.

Quanto à posição de Bobbio, Gramsci (1991) oferece um contraponto, apresentando uma pista para a escolha de um modo de participar que pode conduzir para outro caminho:

[...] é preferível 'pensar' sem disto ter consciência crítica, de uma maneira desagregada e ocasional, isto é, 'participar' de uma concepção de mundo 'imposta' mecanicamente pelo ambiente exterior, ou seja, por um dos vários grupos sociais nos quais todos estão automaticamente envolvidos [...] ou é preferível elaborar a sua própria concepção de mundo de forma crítica, [...] escolher a própria esfera de atividade, participar ativamente na produção da história do mundo, ser o guia de si mesmo e não aceitar do exterior, passiva e servilmente, a marca da própria personalidade? (p.12, grifos meu). 
É possível sim optar pela segunda alternativa, vez que esta vem se tornando um imperativo vital. Mas esta opção implica em criar uma nova cultura, cujas possibilidades ofereçam meios para "difundir criticamente verdades já descobertas, 'socializá-las' [...], transformá-las, portanto, em bases de ações vitais" (Ibid., p. 13). Com esta compreensão se insere a categoria participação como presencial na história, entendida como uma associação de pensamentos, de sentimentos, de ações conjuntas, enfim, um eixo de sustentação da sobrevivência humana. É por meio da participação que os homens se organizam em instituições sociais, nas formas governo, família, escola, igreja, trabalho, todas articuladas pela interdependência visível nos aspectos: crença, burocracia, política e estabelecem relações que dão constituição à sociabilidade humana. Essas relações não são estáticas, não são homogêneas, não são harmônicas, não são lineares. São constituídas num movimento onde a humanidade se produz, se reproduz, tece ideias conjuntas e, ao mesmo tempo entra em contradições.

Nesses termos, o diálogo estabelecido em torno do tema participação como princípio da gestão democrática da educação permite registrar retrocessos, avanços e lacunas, bem como os problemas oriundos de conceitos, concepções, finalidades e práticas diferenciadas, detectando projetos antagônicos de sociedade. E é sempre bom frisar que a participação está entre projetos de sociedade em disputas, daí advém várias possibilidades e variadas práticas, desde um modelo ficcional/ilusória, passando por uma forma mínima, que é a informação, até modelos mais complexos que visam a transformação política e social. Em suma, espera-se que o breve estado do conhecimento delineado venha a propiciar outras luzes na materialização de estudos e pesquisas necessários ao tema participação.

\section{Referências}

ARANDA, M. A. de M. O significado do princípio da participação na política educacional brasileira nos anos iniciais do século XXI: o declarado no PPA "Brasil de Todos 2004-2007”. 236 p. Tese (Doutorado em Educação). Universidade Federal de Mato Grosso do Sul. Campo Grande, MS, 2009.

\section{- A Constituinte Escolar da Rede Estadual de Ensino de Mato Grosso do Sul}

(1999 a 2001): uma proposta de gestão democrática. $184 \mathrm{f}$. (Dissertação de Mestrado, UFMS). Universidade Federal de Mato Grosso do Sul. Campo Grande, 2004.

Projeto Pedagógico e Plano de Desenvolvimento da Escola: buscando a distinção, 2001.78 f. Trabalho de Conclusão de Curso (Especialização) - Campus de Dourados, Universidade Federal de Mato Grosso do Sul, Dourados, 2001.

\section{AVRITZER, L. \& NAVARRO, Z. (Orgs.). A inovação democrática no Brasil: o} orçamento participativo. São Paulo: Cortez. 2003.

BENEVIDES, M. V. de M. A cidadania ativa: referendo, plebiscito e iniciativa popular. São Paulo: Ática, 2000.

BOBBIO, N. O Futuro da Democracia. São Paulo: Paz e Terra, 2002.

BORON, A. A Coruja de Minerva. Petrópolis, Rio de Janeiro: Vozes. 2001.

BRASIL. Ministério da Educação e do Desporto. Conferência Mundial de Educação

para Todos. Jomtien/Tailândia. UNESCO, UNFPA e UNICEF.Brasília: MEC, 1990.

.Plano Decenal de Educação para Todos. Brasília: MEC, 1993. 
Ministério da Educação e do Desporto. Programa Toda Criança na Escola. Brasília: MEC, 1996.

Ministério da Educação e do Desporto. Programa Acorda Brasil! Está na Hora da Escola. Brasília: MEC, 1995.

CAMINI, L. (Org.). Educação pública de qualidade social: conquistas e desafios. Petrópolis: Vozes, 2001.

CARDOSO NETO, O. F. Dissensos no Consenso: a democratização na Escola Pública em Mato Grosso. MT: Editora da UFMT, 2004.

CASTILLA URBINA, M. de. Neoliberalismo y educacion en Nicarágua. Revista Contexto e Educação, Ijui, v. 11, n. 47, p. 92-113, jul./set. 1997.

COSTA, M. de L. de C. Gestão democrática da escola publica: uma questão de qualidade. (Dissertação de Mestrado). Universidade de Brasília, 1994.

COUTINHO, C. N.. A democracia na batalha das idéias e nas lutas políticas do Brasil de hoje. In: FÁVERO, O.; SEMERARO, G. (Orgs.). Democracia e Construção do Público no Pensamento Educacional Brasileiro. Petrópolis, RJ: Vozes, 2002. p. 11-40

DAROS, M. das D. Em busca da participação: a luta dos professores pela democratização da educação. Florianópolis: UFSC, Centro de Ciências da Educação. Núcleo de Publicações, 1999.

DI GIORGI, C. Uma outra escola é possível: uma análise radical da inseção social e da democracia na escola do mundo globalizado. Campinas, SP: Mercado de Letras, 2004.

FERNANDES, M. D. E. Políticas públicas de educação: a gestão democrática na rede estadual de ensino em Mato Grosso do Sul. Campo Grande, MS: Ed. UFMS, 2000.

FIGUEIRA, K. C. N. A política educacional de Mato Grosso do Sul (1991-1994) e os novos paradigmas de produção. (Dissertação de Mestrado). UFMS, 1998.

GIRARDI, N. M. Autonomia da gestão escolar e as funções educacionais do Estado. (Dissertação de Mestrado). Pontifícia Universidade Católica de São Paulo - História e Filosofia da Educação, 1994.

GRAMSCI, A. Os intelectuais e a organização da cultura. (Trad.) Carlos Nelson Coutinho. Rio de Janeiro, RJ: Civilização Brasileira, 1991.

HAGOPIAN, F. The Compromised Consolidation: the Political Class in the Brazilian Transition. In : MAINWARING, S., O'DONNELL, G. \& VALENZUELA, S. (eds.). Issues on Democratic Consolidation:the New South American Democracies in Comparative Perspective. Notre Dame : University of Notre Dame Press, 1992.

KINZO, M. D' A. G. A democratização brasileira: um balanço do processo político desde a transição. Revista Perspectiva, out./dez., vol. 15, n 4, São Paulo, 2001, p. 3-12.

LIMA, A. B. (Org.). Estado e o controle social no Brasil. Uberlândia, MG: Edufu, 2011.

A Participação da Comunidade na Gestão Democrática da Escola em prol da qualidade de ensino: o Projeto Político Pedagógico em questão. Edital 13/2012 (Pesquisa em Educação Básica - Acordo Capes-FAPEMIG). Processo nº: APQ-03536-12. Uberlândia, MG 2012-2015 (em andamento).

MARTINS, C. E. Vinte anos de democracia?Lua Nova, n.64 São Paulo jan./abr. 2005.

MÉSZÁROS, I. O século XXI: socialismo ou barbárie? São Paulo: Boitempo, 2003. 
NEVES, L. M. W. As massas trabalhadoras começam a participar do banquete, mas o cardápio é escolhido à sua revelia, ou democracia e educação escolar nos anos iniciais do século XXI. In: FÁVERO, O. SEMERARO, G. (Orgs.).Democracia e Construção do Público no Pensamento Educacional Brasileiro. Petrópolis, RJ: Vozes, 2002. p. 163174

NOGUEIRA, M. A.. Sociedade civil, entre o político-estatal e o universo gerencial. Revista Brasileira de Ciências Sociais, jun. vol.18, no.52, 2003, p.185-202.

O'DONNELL, G. Delegative Democracy. Journal of Democracy. v. 5, n. 1. Baltimore, 1994. p. 55-69

OLIVEIRA, L. H. H. de.Rumos da democratização brasileira: a consolidação de um modelo majoritário de democracia? Revista de Sociologia e Política, n.15 Curitiba nov., 2000.

RAMOS, J. F. P.. Gestão democrática da escola pública: a experiência do governo das mudanças (1995-2001). Ceará: Editora da UECE. Ceará, 2004.

ROSAR, M. de F. F. A dialética entre a concepção e a prática da gestão democrática da educação básica no Brasil. Educação e Sociologia, vol. 20, nº 69, 1999. p. 165-176

SALES, C. V. As máscaras da democracia: notas sobre a teoria democrática contemporânea à luz dos eixos dahlsianos.Revista Sociologia e Política, jun. no.24, 2005., p.233-245

SENNA, E.. Educação e Democracia:um estudo dessa articulação na produção pedagógica dos anos 80. (Tese de Doutorado). Universidade de São Paulo. São Paulo, 1994.

SETUBAL, M. A. Escola como espaço de encontro entre políticas nacionais e locais. Cadernos de Pesquisa, n. 102, p. 121-133, nov. São Paulo, 1997.

SILVA, J. M. da. Democracia e educação: a alternativa de participação popular na administração escolar. (Tese de Doutorado).Universidade de são Paulo - USP, 1990.

SILVA, T. da. Da participação que temos à que queremos: o processo do orçamento participativo na cidade do Recife. In. AVRITZER, L. \& NAVARRO, Z. (Orgs.). A inovação democrática no Brasil: o orçamento participativo. São Paulo: Cortez. 2003.

SPÓSITO, M. P.. Educação, gestão democrática e participação. Revista Educação e Realidade. jan./jun., Porto Alegre: Faculdades de Educação da UFRGS, 1990. p. 52-56

TUPPY, M. I. N. A educação em confronto com a qualidade. (Tese de Doutorado). Universidade Estadual de Campinas, 1998.

WEFFORT, F. C.. Novas democracias. Quais democracias? In: Qual democracia? São Paulo: Companhia das Letras, 1992.

\section{Notas}

\footnotetext{
1 Docente do Programa de Pós-Graduação em Educação da Universidade Federal da Grande Dourados PPGEDU/UFGD Pós-Doutoranda -PNPD/CAPES/PPGED/UFU mariaaranda@ufgd.edu.br
}

Recebido em Janeiro/2014

Aprovado em Fevereiro/ 2014 